\title{
Bioleaching and Electrochemical Leaching of a Pyritic Chalcopyrite Concentrate
}

\author{
Mohammad Khoshkhoo ${ }^{1, a}$, Mark Dopson ${ }^{2, b}$, Åke Sandström ${ }^{1, c}$ \\ ${ }^{1}$ Division of Sustainable Process Engineering, Luleå University of Technology, 97187 Luleå, \\ Sweden \\ ${ }^{2}$ Centre for Ecology and Evolution in Microbial Model Systems, Linnaeus University, 39182 \\ Kalmar, Sweden \\ a mohammad.khoshkhoo@ltu.se, b mark.dopson@Inu.se, c ake.sandstrom@ltu.se,
}

\section{Keywords: Chalcopyrite; Bioleaching; Mechanism; Moderate thermophiles; Electrochemical cell}

\begin{abstract}
Moderately thermophilic bioleaching of a pyritic chalcopyrite concentrate was mimicked in an electrochemical vessel. The bioleaching was carried out for 28 days at $45^{\circ} \mathrm{C}$ with $2.5 \%$ (wt/vol) solid content at $\mathrm{pH}$ 1.5. Data from the redox potential development was used to program a redox potential controller in an electrochemical vessel to reproduce the same leaching conditions in the absence of microorganisms. Despite precipitation of iron as jarosite and formation of elemental sulphur in the electrochemical experiment, the copper recoveries were almost the same in both experiments.
\end{abstract}

\section{Introduction}

Chalcopyrite is both the most important and the most difficult to leach copper mineral. The main reason for the slow rate of chalcopyrite dissolution is the formation of a layer on the surface of the mineral that hinders dissolution, termed "passivation" [1]. The nature of this layer is still under debate with jarosite, elemental sulphur, non-stoichiometric polysulphides and iron-poor sulphides being the main candidates [2].

Bioleaching is considered to be a very attractive process for extraction of copper from low grade copper sources. Bacterial heap leaching of secondary copper minerals (covellite and chalcocite) are currently practiced on an industrial scale, while its use for chalcopyrite is limited, mostly due to the passivation problem [1]. Therefore, along with investigating the nature of the passivating layer, it is necessary to investigate the interaction between the microorganisms and chalcopyrite.

The mechanism by which chalcopyrite is oxidised in the presence of microorganisms is not fully understood [2]. Many authors have tried to investigate the mechanism by comparing the leaching efficiency of different sulphide minerals in the absence and presence of microorganisms [3]. Most of these studies suffer from a lack of accurate redox potential control in their abiotic experiments. As a result, data comparing biotic and abiotic systems does not conclusively support a bioleaching mechanism. By using an electrochemical cell equipped with a redox potential controller, Harvey and Crundwell overcame this problem [4]. Using this method, Fowler et al. further investigated the mechanism for pyrite bioleaching with a pure culture of Acidithiobacillus ferrooxidans and established that the rate of pyrite dissolution increases in presence of the bacteria [5]. In another investigation, Fowler and Crundwell performed similar experiments on sphalerite and concluded that the bacterial activity only increases the dissolution rate at a high concentration of ferrous ions [6].

In this study, redox potential data from a moderately thermophilic batch bioleaching of chalcopyrite were used to mimic the redox potential development in an electrochemical cell in order to reproduce the same leaching conditions without the presence of microorganisms. This is the first study of its kind to investigate chalcopyrite leaching under controlled, variable redox potentials. 


\section{Experimental}

Material. A copper concentrate from the Boliden owned Kristineberg mine in Sweden was used. The concentrate contained $23.6 \%$ copper, $34.7 \%$ iron, $37.5 \%$ sulphur, $2.1 \%$ zinc and $0.7 \%$ lead. Xray diffraction analysis revealed the presence of chalcopyrite, pyrite and sphalerite in the concentrate. Calculated mineralogy gave the approximate composition as: $68 \%$ chalcopyrite, $26 \%$ pyrite, $3.2 \%$ sphalerite and $0.8 \%$ galena. The concentrate was ground to a particle size with $\mathrm{d}_{80}$ of minus $45 \mu \mathrm{m}$ before it was added into the reactor.

Microorganisms. A mixed culture of moderately thermophilic acidophiles was grown in mineral salt medium (MSM) containing, per litre, $3 \mathrm{~g}\left(\mathrm{NH}_{4}\right)_{2} \mathrm{SO}_{4}, 0.1 \mathrm{~g} \mathrm{KCl}, 0.01 \mathrm{~g} \mathrm{CaNO}{ }_{3} \cdot 4 \mathrm{H}_{2} \mathrm{O}, 0.5 \mathrm{~g}$ $\mathrm{MgSO}_{4} \cdot 7 \mathrm{H}_{2} \mathrm{O}, 0.05 \mathrm{~g} \mathrm{~K}_{2} \mathrm{HPO}_{4}$ and $3.3 \mathrm{~g} \mathrm{Na}_{2} \mathrm{SO}_{4}$ at $45{ }^{\circ} \mathrm{C}$. The copper concentrate was gradually added to the adaptation bioreactor up to a solid content of $2.5 \%(\mathrm{wt} / \mathrm{vol})$.

Bioleaching. A batch bioleaching experiment was performed in a $2 \mathrm{~L}$ baffled reactor at $45^{\circ} \mathrm{C}$. Air at a rate of $1 \mathrm{~L} / \mathrm{min}$ was blown into the reactor. The reactor was inoculated with $10 \%$ (vol/vol) of the active microbial culture and $2.5 \%(\mathrm{wt} / \mathrm{vol})$ of the concentrate. The redox potential was regularly recorded using a platinum electrode with a $\mathrm{Ag} / \mathrm{AgCl}$ reference electrode (Metrohm). The $\mathrm{pH}$ was frequently checked and adjusted to 1.5 by addition of $5 \mathrm{M}$ sulphuric acid or $5 \mathrm{M}$ sodium hydroxide solution. Samples were taken at regular intervals for analysis of dissolved copper and iron as well as total iron. At day 28 , the experiment was terminated and the pulp filtered. The residue was dried overnight and saved for further analysis. In order to validate the activity of the culture, an abiotic experiment under the same conditions was performed, where $0.8 \mathrm{~g} / \mathrm{L}$ (wt/vol) of thymol was used for prohibition of bacterial activity.

Electrochemically controlled leaching. A controlled redox potential leaching was carried out in a similar electrochemical cell as described by Harvey and Crundwell [4]. The development of redox potential over time in the bioleaching experiment was modelled and the results used to program the redox controller of the electrochemical vessel. The leaching was performed at the cathode side of the vessel, where oxygen or hydrogen peroxide was used as the oxidising agent. The electrical current kept the redox potential on the set value by reduction of ferric ions to ferrous. Leaching conditions were kept the same as in the bioleaching experiment. Before grinding of the concentrate, it was kept at $110^{\circ} \mathrm{C}$ for two hours to prohibit the activity of microorganisms.

Chemical analysis. Dissolved iron and copper were analysed by atomic adsorption spectroscopy (AAS; Perkin Elmer, Analyst 100). Total iron was analysed by mixing representative pulp samples with $\mathrm{HCl}$ to a concentration of $6 \mathrm{M}$ for dissolution of precipitated iron and then analysed by AAS. Cyanolysis was used to determine the elemental sulphur content in the final residues [7].

\section{Results and Discussion}

The redox potential in the electrochemically controlled experiment was close to the measured values during the bioleaching experiment (Fig. 1). However, control of the redox potential in the electrochemical vessel was interrupted on days 21 and 27. Although the concentration of total iron during the course of the experiments was slightly higher in the electrochemical leaching compared to the bioleaching, the difference was not significant (Fig. 2). However, irreversible iron precipitation in the electrochemical leaching occurred after day 21, when the redox potential control was interrupted and the redox potential went up to $680 \mathrm{mV}$ and stayed there for around half a day. This appeared to be long enough for seeds of jarosite to form and grow. 


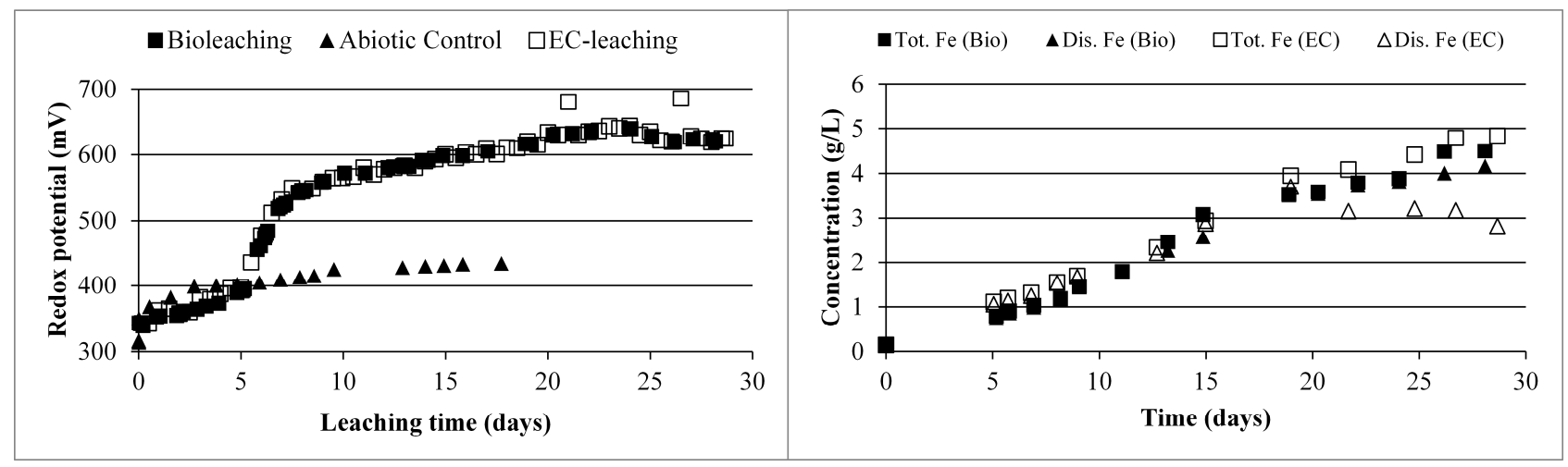

Fig. 1. Measured redox potential (vs. $\mathrm{Ag} / \mathrm{AgCl}$ ) during bioleaching (ロ), abiotic control experiment $(\boldsymbol{\Delta})$ and electrochemical leaching $(\square)$.
Fig. 2. Fe concentration during bio- and electrochemical leaching: Total iron in bioleaching $(\boldsymbol{\square})$, dissolved iron in bioleaching ( $\mathbf{\Delta})$, total iron in electrochemical leaching $(\square)$ and dissolved iron in electrochemical leaching $(\Delta)$.

XRD analysis of the electrochemical leaching residue confirmed that beside chalcopyrite, the only detectable iron compound was jarosite though it was not detected in the bioleaching experiment residue (data not shown). The dissolved iron concentration in the electrochemical experiment fell to around $3 \mathrm{~g} / \mathrm{L}$ which was mostly as ferric ion as the redox potential was over 600 $\mathrm{mV}(\mathrm{Ag} / \mathrm{AgCl})$. A number of studies have shown that the leaching rate is not influenced by ferric ion concentration when it exceeds $0.01 \mathrm{M}$ [8]. Furthermore, the rate of copper dissolution in the electrochemical leaching was not influenced by the formation of jarosite from day 21 onwards (Fig. 3).

The final copper recovery in the bioleaching and the electrochemical leaching was $47 \%$ and $50 \%$, respectively (Fig. 3). The slight difference between the leaching efficiencies in the presence and absence of bacteria suggests that irrespective of the mechanism of ferrous to ferric oxidation (bacterial versus chemical oxidation), the efficiency of leaching remains the same. Besides, the recovery of copper versus time exhibited an almost linear relation in both the bioleaching and the electrochemical leaching with no sign of passivation in either experiment. This lack of passivation was possibly due to the presence of pyrite that improved copper dissolution via a galvanic effect between chalcopyrite and pyrite where pyrite serves as a cathode and chalcopyrite acts as an anode and is oxidised [9].

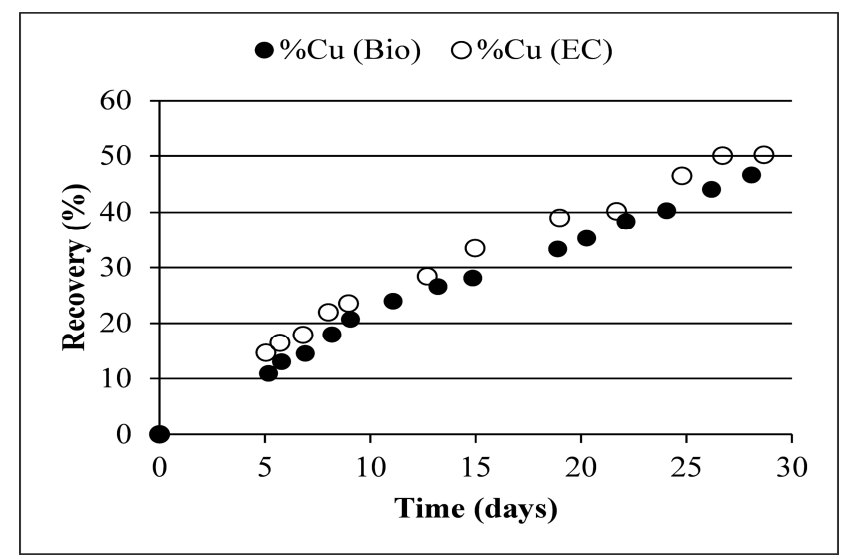

Fig.3. Copper recovery during bioleaching $(\bullet)$ and electrochemical leaching (०). 
Sulphur analysis revealed that in the bioleaching experiment residue, due to bacterial oxidation of elemental sulphur, there was less than $1 \%$ elemental sulphur whereas there was $15 \%$ elemental sulphur in the residue from the electrochemical experiment. This implies that sulphur formed on the chalcopyrite surface did not hinder the transportation of ions to and from the chalcopyrite surface. It neither did impair the electrical contact necessary between chalcopyrite and pyrite for formation of the galvanic couple.

It is worth noting that these statements are probably true for a chalcopyrite concentrate containing pyrite under the conditions practiced during these experiments. Similar investigations on pure chalcopyrite concentrate at different temperatures would give more insight into the mechanism of interaction between microorganisms and chalcopyrite.

\section{Summary}

Moderately thermophilic bioleaching of a pyritic chalcopyrite concentrate was mimicked in absence of bacteria in an electrochemical vessel. It was shown that both recovery and rate of copper dissolution in the bioleaching experiment were the same as in the electrochemical experiment. The oxidation of elemental sulphur by bacteria did not improve the rate of leaching, nor did jarosite precipitation in the electrochemical test have negative effect on copper dissolution.

\section{References}

[1] Sandström Å, Shchukarev A, Paul J. XPS characterisation of chalcopyrite chemically and bioleached at high and low redox potential. Minerals Engineering 18 (2004) 505-515.

[2] Debernardi G, Carlesi C. Chemical-electrochemical approaches to the study passivation of chalcopyrite. Miner Process Extr Metal Rev 34 (2013) 10-41.

[3] Crundwell FK. How do bacteria interact with minerals? Hydrometallurgy 71 (2003) 75-81.

[4] Harvey PI, Crundwell FK. Growth of Thiobacillus ferrooxidans: a novel experimental design for batch growth and bacterial leaching studies. Applied and Environmental Microbiology 63 (1997) 2586-2592.

[5] Fowler TA, Holmes PR, Crundwell FK. Mechanism of pyrite dissolution in the presence of Thiobacillus ferrooxidans. Applied and Environmental Microbiology 65 (1999) 2987-2993.

[6] Fowler TA, Crundwell FK. Leaching of zinc sulfide by Thiobacillus ferrooxidans: Bacterial oxidation of the sulfur product layer increases the rate of zinc sulfide dissolution at high concentrations of ferrous ions. Applied and Environmental Microbiology 65 (1999) 5285-5292.

[7] Hazeu W, Batenburg-van dV, Bos P, Pas RK, Kuenen JG. The production and utilization of intermediary elemental sulfur during the oxidation of reduced sulfur compounds by Thiobacillus ferrooxidans. Archives of Microbiology 150 (1988) 574-579.

[8] Córdoba EM, Muñoz JA, Blázquez ML, González F, Ballester A. Leaching of chalcopyrite with ferric ion. Part I: General aspects. Hydrometallurgy 93 (2008) 81-87.

[9] Koleini SMJ, Aghazadeh V, Sandström A. Acidic sulphate leaching of chalcopyrite concentrates in presence of pyrite. Minerals Engineering 24 (2011) 381-386. 